\title{
Estudo das características de revestimentos poliméricos aplicados por aspersão térmica para proteção contra desgaste e corrosão de substratos metálicos
}

\section{(Study of the characteristics of thermally sprayed polymer coatings for wear and corrosion protection of metallic substrates)}

\author{
Carlos Roberto Camello Lima ${ }^{1}$, Natália Ferraresso Cardoso de Souza ${ }^{1}$, Flávio Camargo ${ }^{2}$ \\ ${ }^{1}$ UNIMEP - Universidade Metodista de Piracicaba, Faculdade de Engenharia, Santa Barbara d'Oeste, SP, Brasil, \\ crclima@unimep.br,nafsouza@unimep.br \\ 2OGRAMAC Engenharia de Superficies, Santo Antônio de Posse, SP, Brasil, flavio@ogramac.com.br
}

\begin{abstract}
Resumo
Revestimentos poliméricos vêm sendo crescentemente considerados como solução na proteção de materiais metálicos contra corrosão e desgaste. A tecnologia de aspersão térmica permite a aplicação de polímeros sobre diversos materiais de substrato, em diversas espessuras, para várias condições ambientais. Polímeros depositados por este processo têm potencial, tanto para reduzir custos com materiais, como para melhorar o desempenho do revestimento em ambientes agressivos. Neste trabalho, foram aplicados revestimentos poliméricos poli-éter-éter-cetona (PEEK) e Poliamida 12 sobre substratos de aço carbono, utilizando o processo de aspersão térmica a chama de baixa velocidade. Revestimentos de alta qualidade foram obtidos por esta técnica. Foram avaliadas as características dos materiais e dos revestimentos obtidos, especialmente quanto às propriedades mecânicas, de desgaste e corrosão. De acordo com os resultados obtidos, pode-se afirmar que os revestimentos estudados podem ser utilizados com sucesso em aplicações que envolvam desgaste e corrosão, com uma pequena vantagem para o polímero PEEK.
\end{abstract}

Palavras-chave: Revestimentos; Aspersão Térmica; Polimeros; Desgaste, Corrosão.

Abstract: Polymer coatings have been widely considered as a solution in the protection of metallic substrates against both wear and corrosion. Thermal spray technology allows the deposition of polymers onto several substrate materials for various thicknesses at several environmental conditions. Thermal sprayed polymers have high potential for material cost reduction as well as to improve coating performance in drastic environments. In this work, poly-ether-ether-ketone (PEEK) and Polyamide 12 were flame sprayed on carbon steel substrates. High quality coatings were obtained. Several tests were carried out to evaluate the coatings mainly related to wear and corrosion performance. According to the obtained results, it can be stated that the studied coatings can be successfully used in applications involving wear and corrosion, with a slight edge for the PEEK polymer.

Key-words: Coatings; Thermal Spray; Polymers; Wear; Corrosion.

\section{Introdução}

A aspersão térmica é uma tecnologia de aplicação de revestimentos utilizada em diversas áreas da engenharia. Seus diferentes métodos de aplicação e a grande variedade de materiais utilizados fazem desta tecnologia uma das mais conceituadas para soluções relacionadas a desgaste, corrosão e degradação térmica, entre outras aplicações. Sua utilização é ampla, tanto na fabricação, como na manutenção de peças e componentes. Com a grande diversificação e o crescente desenvolvimento relacionado aos materiais para deposição, a combinação de diferentes métodos de deposição para diferentes tipos de materiais abre larga perspectiva para aplicações em projetos de

(Recebido em 02/04/2012; Texto final em 24/07/2012). engenharia. É necessário, na perspectiva do projeto, levar em conta que o processo é sinergístico, ou seja, a combinação de fatores do processo produz um efeito muito maior que o esperado quando considerados tais fatores individualmente [1,2].

Esta tecnologia de revestimentos é caracterizada por alta adesão, compatibilidade para uso com diversos tipos de materiais de substrato e baixa porosidade. As diferentes variações das técnicas de aspersão térmica permitem que se escolha aquela mais compatível com as restrições do substrato, como sua temperatura e espessura. Esses revestimentos e substratos possuem características únicas quanto a dilatação térmica, ponto de fusão e compatibilidade química durante a deposição. Materiais que se decompõe facilmente tendem a ser pobres candidatos a revestimentos. Assim, a maioria dos metais, ligas, todas as formas de cerâmica e alguns polímeros são utilizados na aspersão térmica $[2,3,4]$.

As variações básicas do processo ocorrem nos materiais de aspersão utilizados, no método de aquecimento e no método de propulsão dos materiais no substrato. Muitos metais, cerâmicas, 
compostos intermetálicos, alguns polímeros e certos vidros podem ser depositados por um ou mais dos vários processos de aspersão térmica [5].

Revestimentos produzidos por aspersão térmica têm grande importância em aplicações que exigem elevada resistência ao desgaste e à corrosão, principalmente nas indústrias de vanguarda, como aeroespacial, aeronáutica, automobilística e eletroeletrônica. No cenário de grande diversidade de opções, é fundamental levar-se em conta as variáveis econômicas e de produtividade que, muitas vezes, se sobrepõem à pura solução técnica. Desta forma, estudar métodos de deposição e opções de materiais numa mesma aplicação torna-se extremamente relevante e oportuno. Segundo Davis [3], a seleção do método adequado é geralmente determinada pelo tipo de revestimento desejado, desempenho do revestimento, economia e tamanho da peça.

Um dos métodos mais tradicionais e simples de aplicação por aspersão térmica, pertencente ao grupo de combustão [2], é o processo de aspersão por chama convencional. $\mathrm{O}$ método de aspersão térmica por chama convencional, conhecido como flame spray, usa a energia química de combustão de um gás combustível em oxigênio como fonte de aquecimento para fundir o material de revestimento. O princípio de funcionamento pode ser observado na Figura 1, que ilustra o uso de pós como material de alimentação.

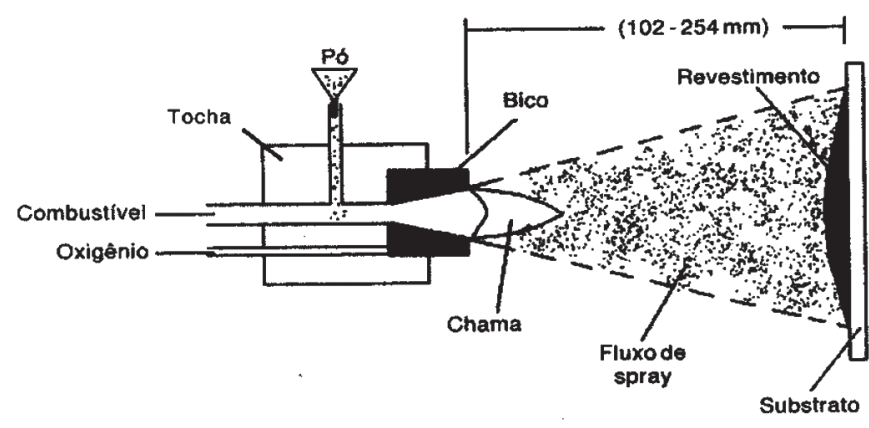

Figura 1. Esquema de aspersão por chama de pós [2]

As tochas de aspersão por chama podem ser adaptadas para usar diversas combinações de gases, tendo em vista a otimização dos custos e a qualidade do revestimento. Os gases comumente usados são acetileno, propano, gás metil-acetilenopropadieno (MAPP) e hidrogênio, combinados com o oxigênio. Os materiais de deposição podem estar sob a forma de arames, varetas, cordões ou pós. Praticamente, é necessária somente a mudança de bico e da "tampa de ar" (air cap) para se adaptar a tocha a diferentes ligas, gases ou tamanhos de arames $[1,3]$.

\subsection{Revestimentos poliméricos}

Diversos polímeros têm sido considerados na aplicação de revestimentos. Dentre os plásticos de engenharia, as poliamidas (PA) se destacam, pois se caracterizam por suas ótimas propriedades mecânicas e outras qualidades, como resistência a exposição atmosférica, baixo coeficiente de atrito, alta temperatura de fusão, boa resistência ao impacto e alta resistência a fadiga. Adicionalmente, também possuem uma ótima resistência aos solventes orgânicos, exceto alguns como o acido fórmico, m-cresol, por exemplo [6].

Nos polímeros, enquanto a fusão é uma transição na qual a fase cristalina perde sua estrutura repetitiva, a transição vítrea (Tv) pode ser entendida como um ganho de mobilidade da fase desordenada. Mudanças bruscas em outras propriedades físicas acompanham essa transição vítrea, como, por exemplo, a rigidez, a capacidade calorífica e o coeficiente de expansão térmica [7].

As temperaturas de fusão e de transição vítrea são parâmetros importantes em relação às aplicações de serviço dos polímeros. Elas definem, respectivamente, os limites de temperatura superior e inferior para numerosas aplicações, especialmente no caso de polímeros semicristalinos [8].

A poliamida 12 (PA 12) é uma poliamida alifática e suas principais propriedades são mostradas na Tabela 1 .

Tabela 1. Propriedades da Poliamida 12 [6].

\begin{tabular}{|l|c|}
\hline Propriedades & PA 12 \\
\hline Temperatura de fusão $\left({ }^{\circ} \mathrm{C}\right)$ & 177 \\
\hline Densidade $\left(\mathrm{g} / \mathrm{cm}^{3}\right)$ & 1,02 \\
\hline Resistência à tração $(\mathrm{MPa})$ & 52 \\
\hline Módulo de flexão $(\mathrm{MPa})$ & 1172 \\
\hline Absorção de água $(\%)$ em 24 hs de imersão & 0,25 \\
\hline
\end{tabular}

Segundo Wiebeck e Harada [6], as policetonas são um grupo de resinas termoplásticas conhecidas no mercado como poli-éter-cetona (PEK) e a poli-éter-éter-cetona (PEEK). São polímeros cristalinos, possuindo alta temperatura de resistência para utilização, na faixa de $240^{\circ} \mathrm{C}$ a $245^{\circ} \mathrm{C}$. Os dois têm similares desempenhos mecânicos. O PEEK se auto extingue com baixa emissão de fumaça, boa resistência química e estabilidade hidrolítica, mas seu custo é alto comparando com outros termoplásticos.

As policetonas possuem excepcional resistência a altas temperaturas (acima de $260^{\circ} \mathrm{C}$ ), excepcional resistência química, excelentes propriedades mecânicas e alta resistência ao desgaste. Oferecem uma grande faixa de variedades de opções custo/desempenho. Esses materiais têm boas propriedades dielétricas, com alto volume e alta resistência elétrica, e alta resistência dielétrica. A Tabela 2 apresenta as propriedades do PEEK, revestimento utilizado no estudo.

Tabela 2. Propriedades do Poli-éter-éter-cetona [9].

\begin{tabular}{|l|c|}
\hline Propriedades & PEEK \\
\hline Temperatura de fusão $\left({ }^{\circ} \mathrm{C}\right)$ & 343 \\
\hline Densidade $\left(\mathrm{g} / \mathrm{cm}^{3}\right)$ & 1,37 \\
\hline Resistência à tração $(\mathrm{MPa})$ & 188 \\
\hline Alongamento na tração $(\%)$ & 2 \\
\hline Temperatura de deflexão térmica (HDT) $\left({ }^{\circ} \mathrm{C}\right)$ & 326 \\
\hline
\end{tabular}

O objetivo deste trabalho é realizar um estudo comparativo das propriedades de revestimentos poliméricos depositados por 
aspersão térmica, principalmente objetivando sua aplicação em ambientes com solicitações de desgaste e corrosão. Serão avaliadas a micro e macro dureza superficial dos revestimentos, a resistência ao desgaste abrasivo e a resistência à corrosão em meio ácido.

\section{Materiais e Métodos}

Os materiais, na forma de pó, utilizados neste estudo foram o polímero poli-éter-éter-cetona- PEEK (Victrex ${ }^{\circledR}$ PEEK $^{\mathrm{TM}}$ ) e poliamida 12 ou PA 12 (EVONIK). Amostras de aço carbono AISI 1020 , com dimensões de 100 x $50 \mathrm{~mm}$ x $5 \mathrm{~mm}$, foram utilizadas como substratos. O processo de aspersão selecionado para a deposição foi o processo a chama convencional (flame spray), utilizando um equipamento Terodyn-2000. Imediatamente antes de aplicar o revestimento, as amostras foram jateadas com óxido de alumínio para remover as impurezas e aumentar a rugosidade [5]. No processo de aspersão foram utilizados os parâmetros mostrados na Tabela 3.

Tabela 3. Parâmetros principais utilizados no processo de aspersão.

\begin{tabular}{|l|c|c|}
\hline Aspersão a Chama (Terodyn 2000) & PEEK & PA 12 \\
\hline Taxa de fluxo de Oxigênio $\left(1 . \mathrm{min}^{-1}\right)$ & 54 & 54 \\
\hline Taxa de fluxo de Acetileno $\left(1 . \mathrm{min}^{-1}\right)$ & 27 & 27 \\
\hline Pressão do Gás Oxigênio (Psi) & 30 & 30 \\
\hline Pressão do Gás Acetileno (Psi) & 30 & 30 \\
\hline Taxa de alimentação do pó $\left(\mathrm{g} \cdot \mathrm{min}^{-1}\right)$ & 12 & 10 \\
\hline Distância de aspersão - Standoff Distance $(\mathrm{mm})$ & 85 & 85 \\
\hline Pré-aquecimento do substrato $\left({ }^{\circ} \mathrm{C}\right)$ & 230 & 230 \\
\hline Rugosidade inicial do substrato $(\mathrm{Ra}, \mu \mathrm{m})$ & 1,6 & 1,6 \\
\hline
\end{tabular}

A temperatura de pré-aquecimento dos substratos antes da aspersão foi determinada por pré-testes e em consonância com por trabalhos anteriores [10]. A distância de aspersão (SOD Stand Off Distance) de $85 \mathrm{~mm}$ foi definida após alguns testes preliminares. Distâncias muito maiores reduzem a espessura dos "salpicos" individuais, a eficiência de deposição, assim como a adesão ao substrato [11]. Após a aplicação do revestimento, as amostras foram resfriadas por imersão em água.

Depois de resfriadas, as amostras foram caracterizadas usando um medidor de espessura Mitutoyo GM-002 e um rugosímetro Mitutoyo SJ-201 P, com o padrão de calibragem OGPR-001. Em seguida, foi realizado o teste de dobramento, de acordo com a norma MIL-STD-2138A, para verificação de trincas no revestimento. Ensaios de dureza foram realizados por macrodureza Shore D e medições de microdureza Vickers. Os resultados são apresentados pela média de 10 leituras. As amostras foram preparadas para avaliação metalográfica por disco de corte diamantado, lixas graduadas e polimento com pasta de diamante.

Foram efetuadas análises por microscopia ótica (MO) e de varredura (MEV). Dois corpos de prova foram preparados para avaliar a resistência ao desgaste dos revestimentos Foram também efetuados ensaios de termogravimetria (TGA) e calorimetria diferencial de varredura (DSC) para verificar o comportamento dos materiais usados sob condições de calor e ambientes adversos. Nas análises de TGA, foi aplicada uma taxa de $20^{\circ} \mathrm{C} / \mathrm{min}$, utilizando Nitrogênio de $30^{\circ} \mathrm{C}$ a $800^{\circ} \mathrm{C}$ e Oxigênio de $800^{\circ} \mathrm{C}$ a $1000^{\circ} \mathrm{C}$. Na análise de calorimetria, foi aplicada uma taxa de $20^{\circ} \mathrm{C} / \mathrm{min}$ utilizando Nitrogênio. Os ensaios de desgaste foram realizados por abrasão a dois corpos (SUGA Teste), utilizando lixa 220 Mesh, carga de $16 \mathrm{~N}$ e com um máximo de 1.200 ciclos. Para avaliação da corrosão, duas amostras de cada um dos revestimentos foram preparadas para o ensaio de imersão em solução de $\mathrm{H}_{2} \mathrm{SO}_{4} 40 \%$, em conformidade com a norma ASTM D1308-02 - 2007 [12].

\section{Resultados e Discussão}

\subsection{Análises Térmicas}

Análise térmica abrange um grupo de técnicas nas quais uma propriedade física ou química de uma substância, ou de seus produtos de reação, é monitorada em função do tempo ou temperatura, enquanto a temperatura da amostra, sob uma atmosfera específica, é submetida a uma programação controlada [13]. Dentre as principais análises térmicas, estão a Termogravimetria (TGA), que mede mudanças de massa devido à interação com a atmosfera, vaporização e decomposição, e a Calorimetria Diferencial de Varredura (DSC), que acompanha processos físicos e químicos envolvendo variação de energia [14].

Nas análises termogravimétricas, foi possível verificar a perda de massa de acordo com a temperatura e atmosfera. $\mathrm{Na}$ Figura 2, pode-se verificar o comportamento das resinas Poliamida 12 e PEEK. Pela análise do termograma do PEEK, na atmosfera de nitrogênio até $800^{\circ} \mathrm{C}$, houve perda de $46,46 \%$ da massa inicial e o restante, $49,63 \%$ até $1000^{\circ} \mathrm{C}$ na atmosfera de oxigênio, sobrando, aproximadamente, $4 \%$ de resíduos. Para o PA 12, na atmosfera inerte, próximo da temperatura de $500^{\circ} \mathrm{C}$, houve perda de $94,84 \%$ da amostra inicial. Já na atmosfera oxidante, houve perda adicional de cerca de $3 \%$, sobrando, aproximadamente, $2 \%$ de resíduos. A decomposição ocorrida está associada à quebra das ligações estáveis $(\mathrm{C}-\mathrm{C})$, ocorrendo ainda em atmosfera inerte.

$\mathrm{Na}$ análise por Calorimetria Diferencial de Varredura (DSC) pode-se verificar as temperaturas das transições e grau de cristalização dos polímeros, mostrados na Figura 3.

$\mathrm{Na}$ análise por DSC do PEEK, é possível verificar a transição vítrea na temperatura de $170^{\circ} \mathrm{C}$, seu grau de cristalização e o valor da energia absorvida (endotérmica) neste ponto. Já na análise do PA 12, é possível verificar seu ponto de fusão cristalino na temperatura de $189^{\circ} \mathrm{C}$, seu grau de cristalização e o valor da energia, referente à mudança de estado. Percebe-se pela análise dos termogramas uma cristalização muito mais acentuada para o revestimento PA 12, em torno de 18\%. Esta característica pode estar refletida na macrodureza do revestimento poliamida (Tabela 3). 


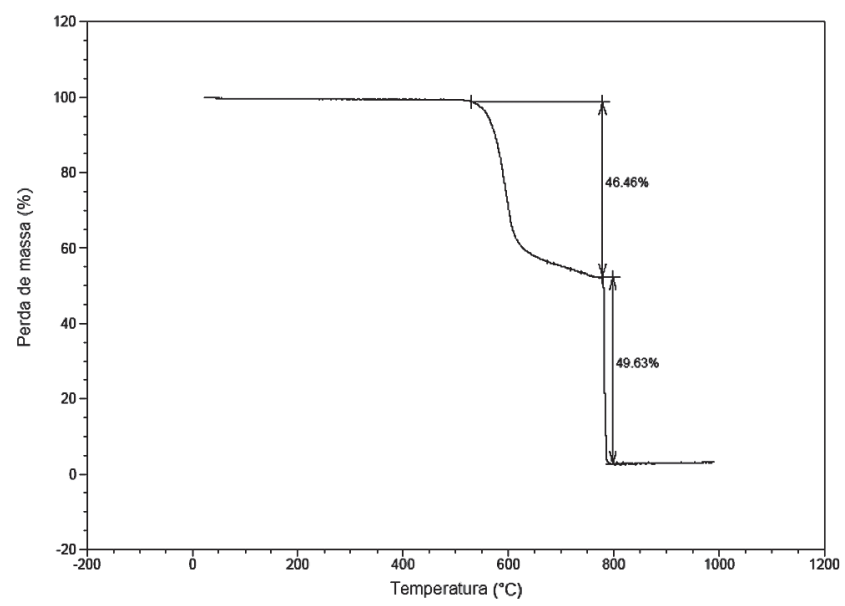

(a)

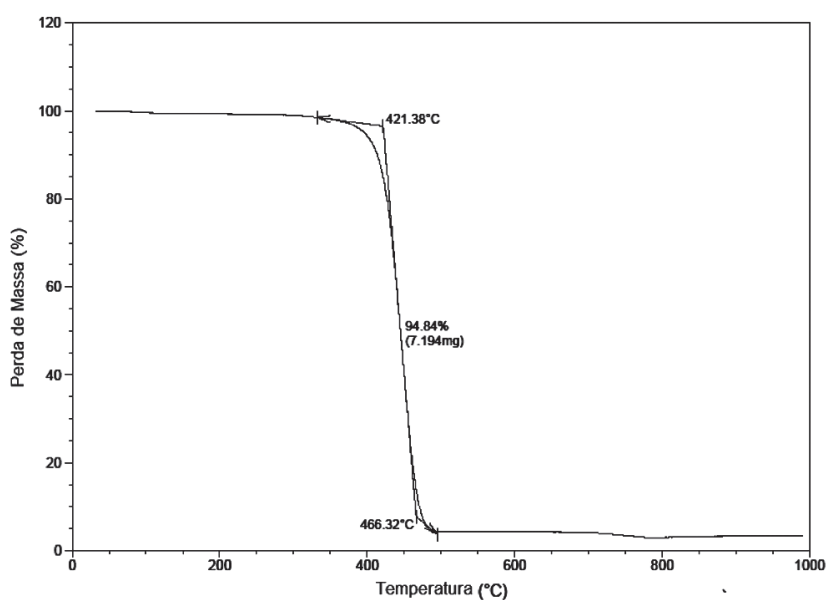

(b)

Figura 2. Termograma da análise de TGA (a) do PEEK e (b) da Poliamida 12.

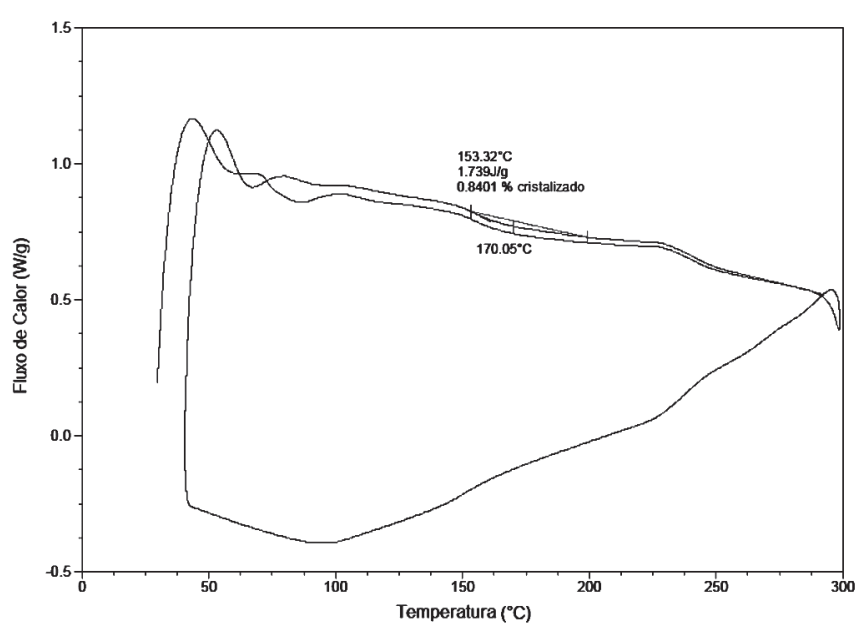

(a)

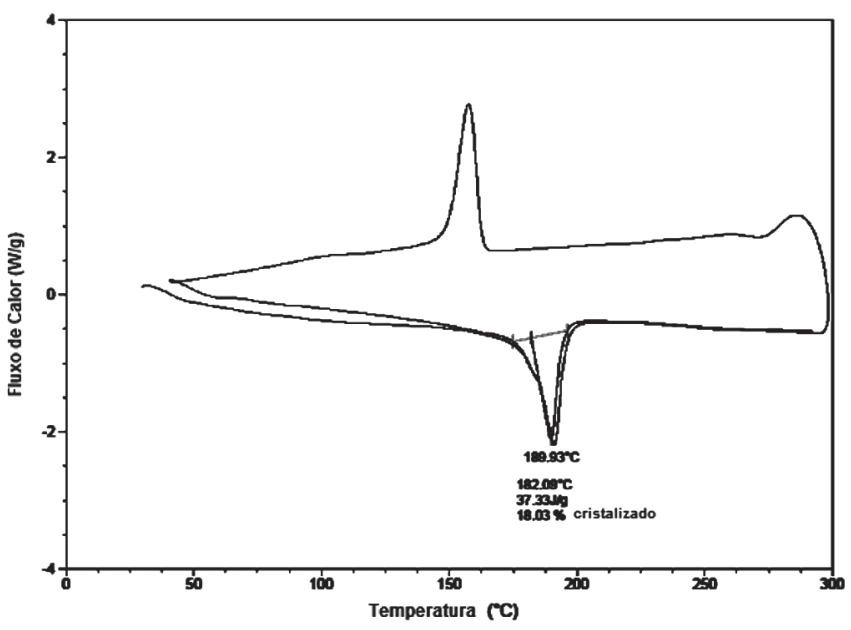

(b)

Figura 3. Termograma da análise de DSC (a) do PEEK e (b) do PA 12.

\subsection{Avaliação da dureza e ductilidade}

Os resultados dos ensaios de dobramento mostraram que as amostras não apresentaram trincas ou defeitos similares. Esse comportamento mostra que a transição vítrea ocorrida nos polímeros levou a uma boa ductilidade, também considerando que o resfriamento acelerado pode ter levado os revestimentos a apresentar fases amorfas, favorecendo a ductilidade. Os resultados para os testes de macrodureza Shore D dureza e microdureza Vickers são apresentados na Tabela 4.

Tabela 4. Resultados das medidas de dureza dos revestimentos

\begin{tabular}{|c|c|c|}
\hline Material & $\begin{array}{c}\text { Macrodureza } \\
\text { Shore D }\end{array}$ & $\begin{array}{c}\text { Microdureza Vickers } \\
\text { (Hv 100) }\end{array}$ \\
\hline PEEK & $82,0 \pm 0,1$ & $18.5 \pm 0,2$ \\
\hline Poliamida 12 & $90,2 \pm 0,3$ & $18.2 \pm 0.5$ \\
\hline
\end{tabular}

$\mathrm{Na}$ comparação dos resultados de dureza, os dois revestimentos apresentam um resultado similar quanto à microdureza, variando cerca de $10 \%$ a mais no resultado de Dureza Shore D para o revestimento com Poliamida 12. Este maior valor de macrodureza pode refletir a maior cristalização ocorrida no revestimento poliamida, como apresentado na Figura 3. A dureza Shore dá uma medida da resistência relativa à penetração para vários polímeros, mas não deve ser usada para prever comportamento em desgaste abrasivo, podendo então ser auxiliada pela medida de microdureza. No ensaio de microdureza, os polímeros apresentam maior dependência dos parâmetros de carga e tempo de indentação, devido principalmente ao comportamento viscoelástico. Porém, sua utilização permite que se tenha uma noção da variação localizada da dureza e da resistência em função da microestrutura formada, conceito que inclui a extensão da cristalinidade, tamanho e distribuição das regiões amorfas e dos cristalitos e sua organização em níveis superiores da estrutura. Pelos resultados da Tabela 1, onde são computados os valores 
médios de dez leituras em distintas regiões da amostra, percebese que não há praticamente diferença na microdureza entre os dois materiais utilizados.

\subsection{Avaliação metalográfica}

Os revestimentos obtidos apresentaram espessura entre 400 e $500 \mu \mathrm{m}$, em média. As Figuras 4 e 5 mostram as seções transversais das amostras do revestimento PA 12 obtidas por microscopia eletrônica de varredura. É possível verificar a interface da amostra, poros existentes e espessura do revestimento Poliamida. Nas Figuras 6 e 7, o mesmo pode ser observado para o revestimento PEEK.

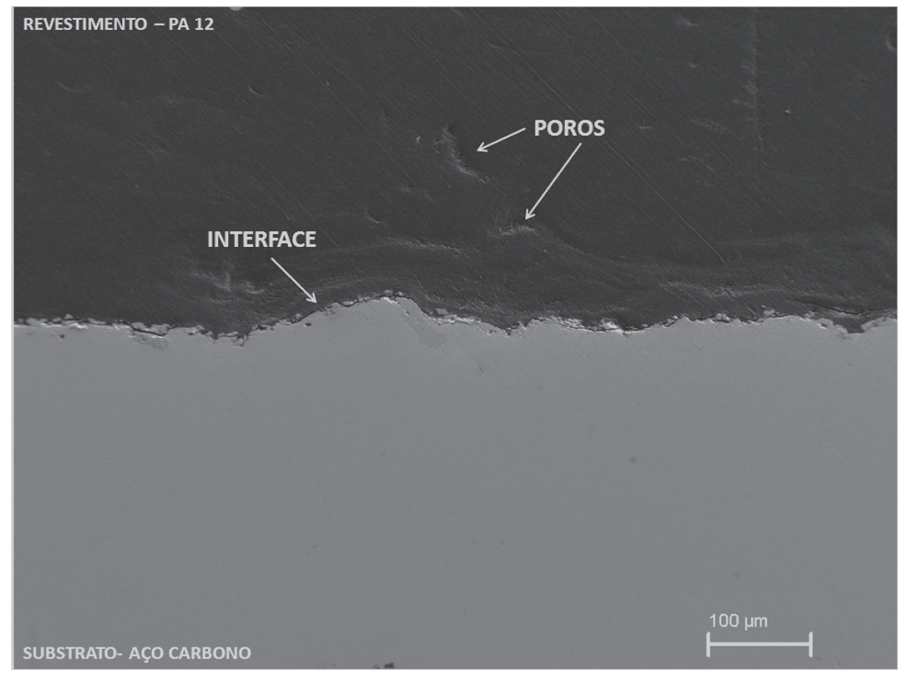

Figura 4. Imagem típica da seção transversal de amostra com revestimento PA 12, mostrando a interface com aderência e a presença de poucos poros

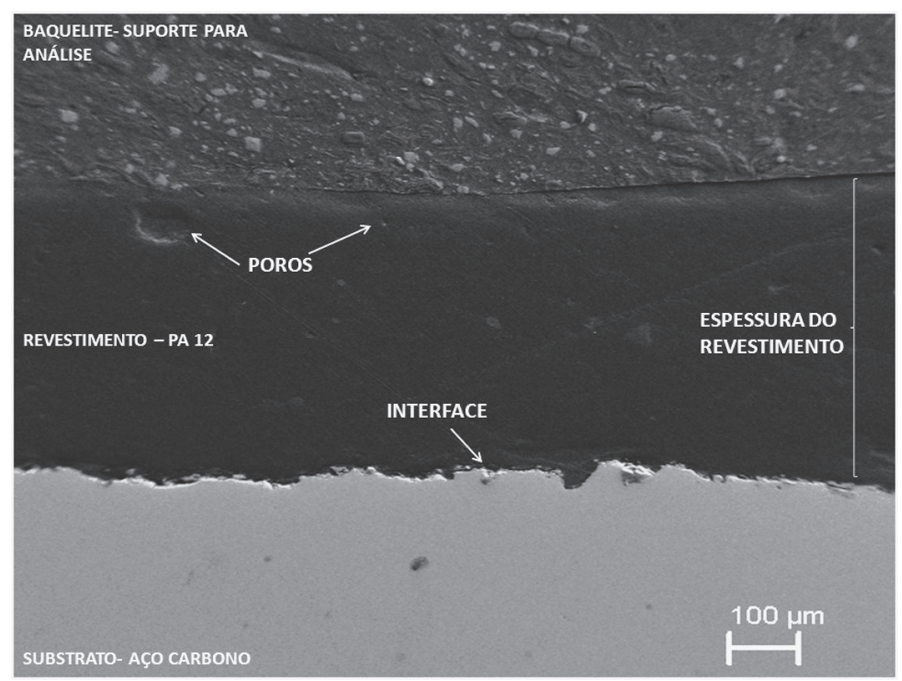

Figura 5. Seção transversal total da amostra de aço carbono com revestimento PA 12 total

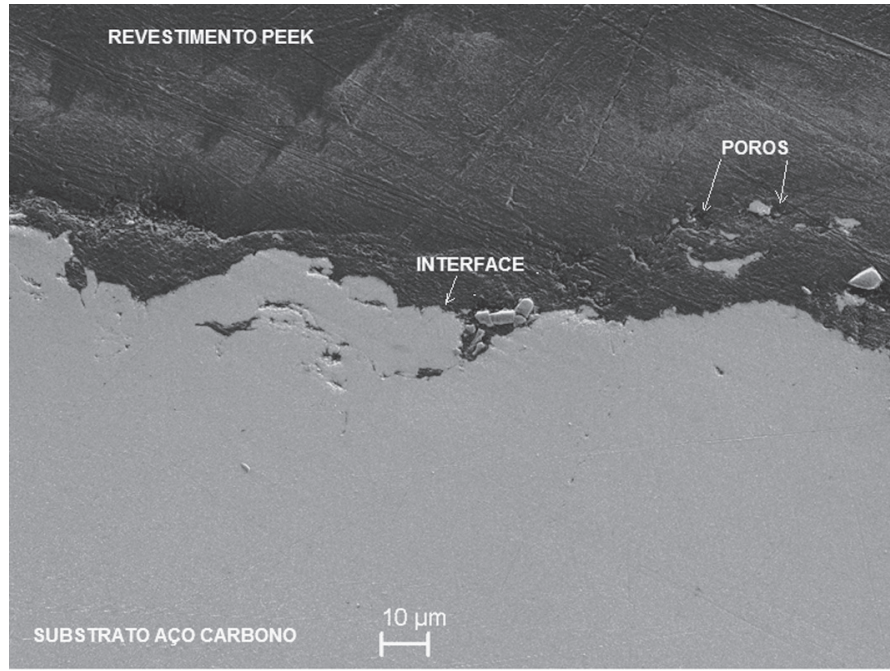

Figura 6. Imagem típica da seção transversal de amostra com revestimento PEEK, mostrando a interface com aderência e a presença de alguns poros.

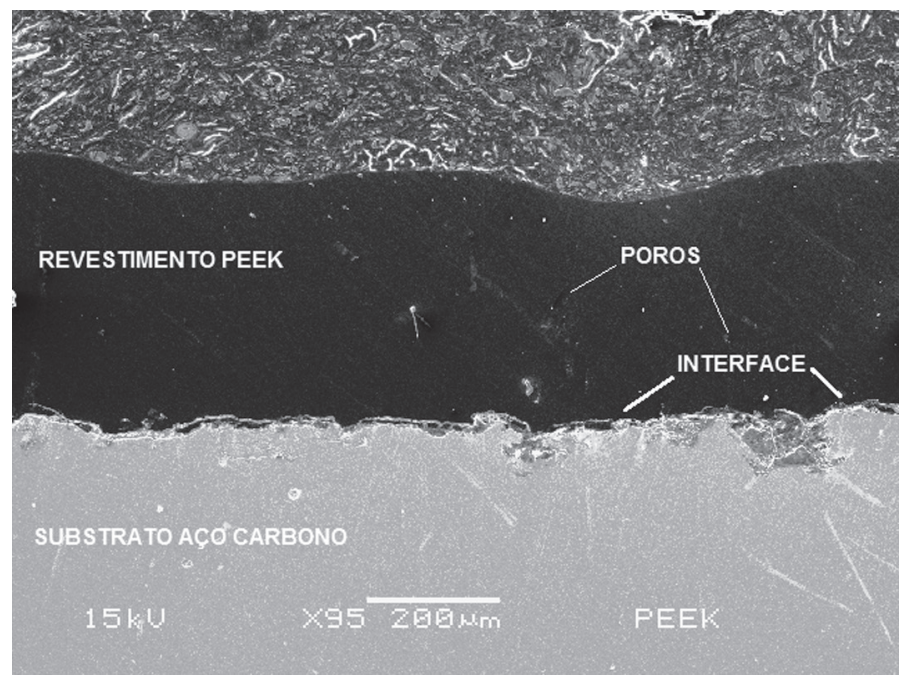

Figura 7. Seção transversal total da amostra com revestimento PEEK.

$\mathrm{Na}$ análise realizada por microscopia ótica e de varredura, auxiliada pela ausência de trincas no ensaio de dobramento, ficou evidente que houve aderência dos revestimentos obtidos pela ausência de delaminação entre revestimento e substrato. Foram observados, ainda, poucos poros e revestimento homogêneo, tanto para o PEEK, quanto para o PA 12. Deve-se ressaltar, porém, que não foram realizadas medidas de aderência ou de percentual de porosidade, sendo estas observações realizadas exclusivamente em função de análise visual das amostras por microscopia ótica e eletrônica.

\subsection{Avaliação de desgaste}

Na Figura 8, podem ser observados os resultados obtidos nos ensaios de desgaste abrasivo (SUGA Teste) em termos da perda de massa acumulada. É possível perceber uma maior evolução da 
perda de massa para uma das amostras de revestimento Poliamida testada. Nos primeiros 400 ciclos do ensaio, a primeira amostra de PA 12 apresentou a maior perda de massa $(12,3 \mathrm{mg})$, enquanto uma das amostras de PEEK sofreu uma perda de apenas 5,3 $\mathrm{g}$, ou seja, menos de $50 \%$ do desgaste apresentado pela amostra PA 12. Porém, a outra amostra apresenta valores similares às duas amostras de revestimento PEEK, sendo inclusive menor entre 800 e 1200 ciclos, com o menor valor acumulado de desgaste $(19,6 \mathrm{mg})$. Esta diferença significativa entre as duas amostras de revestimentos Poliamida poderia ser explicada por diferenças na microestrutura formada, principalmente relacionada ao nível de porosidade e/ou micro trincas.

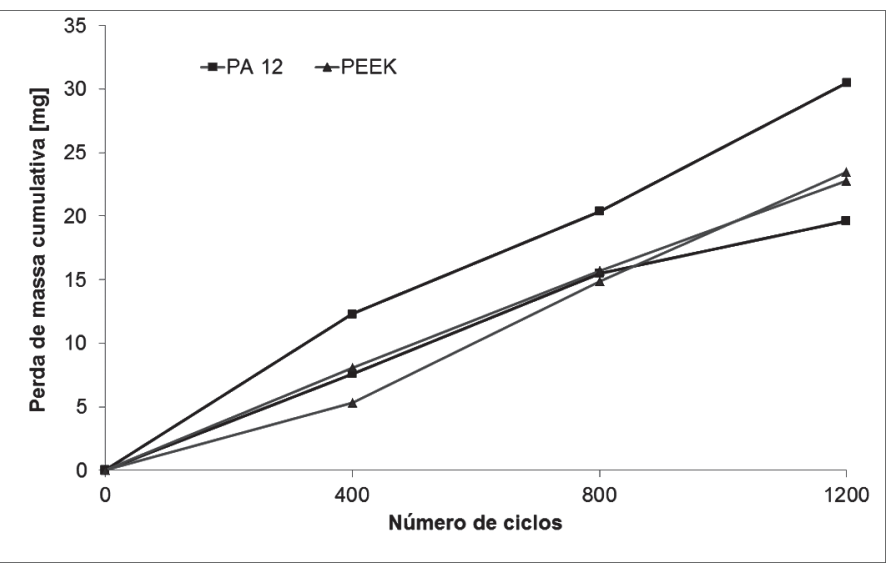

Figura 8. Resultados obtidos no ensaio de desgaste abrasivo SUGA.

\subsection{Avaliação da corrosão}

$\mathrm{Na}$ avaliação da corrosão dos revestimentos, as amostras foram imersas completamente em solução altamente agressiva de $\mathrm{H}_{2} \mathrm{SO}_{4}$ a $40 \%$. Após períodos em torno de 250 horas, as amostras eram avaliadas visualmente, pesadas e recolocadas

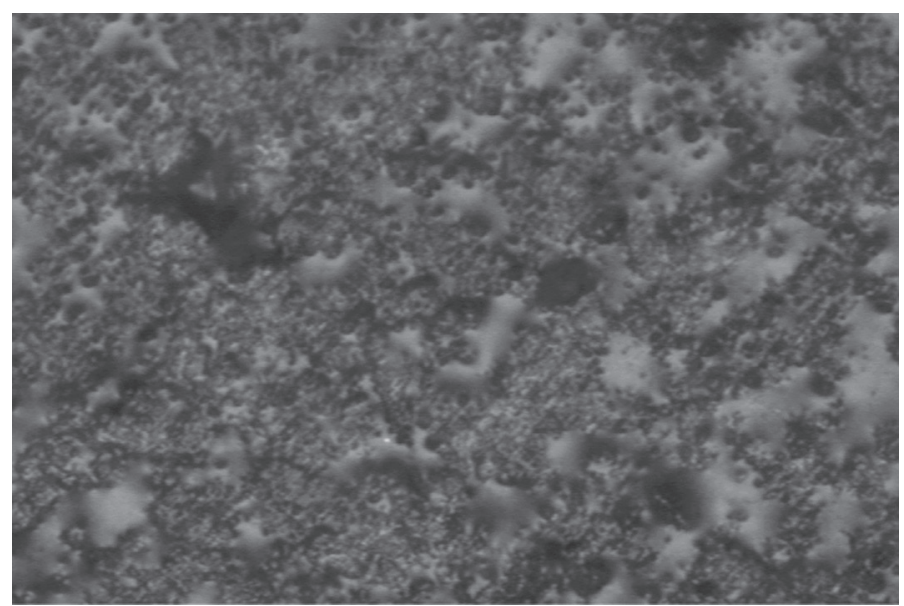

a) na solução. Os resultados de ganho de massa são apresentados na Figura 9. Apesar do ganho de massa ser mínimo, pode-se observar, pela análise rigorosa dos dados da figura, que as duas amostras de revestimento PEEK apresentaram menor ganho de massa, significando menor ataque na solução. Porém, assim como no ensaio de desgaste, uma das amostras de PA 12 (amostra 2) apresentou comportamento bastante similar às amostras de PEEK. O valor de $0,239 \mathrm{~g}$ de ganho de massa com 1.848 horas de imersão para esta amostra, divergente dos demais resultados, pode ter incorporado algum elemento externo na pesagem. $\mathrm{Na}$ análise visual, ambas as amostras não apresentam sinais manifestos de corrosão, o que evidencia sua alta resistência à corrosão. Na avaliação com auxílio de microscopia, é possível perceber alguma alteração na morfologia superficial, como ilustra a Figura 10. A superfície aparentemente mais rugosa do revestimento Poliamida pode implicar um maior ataque corrosivo superficial neste material.

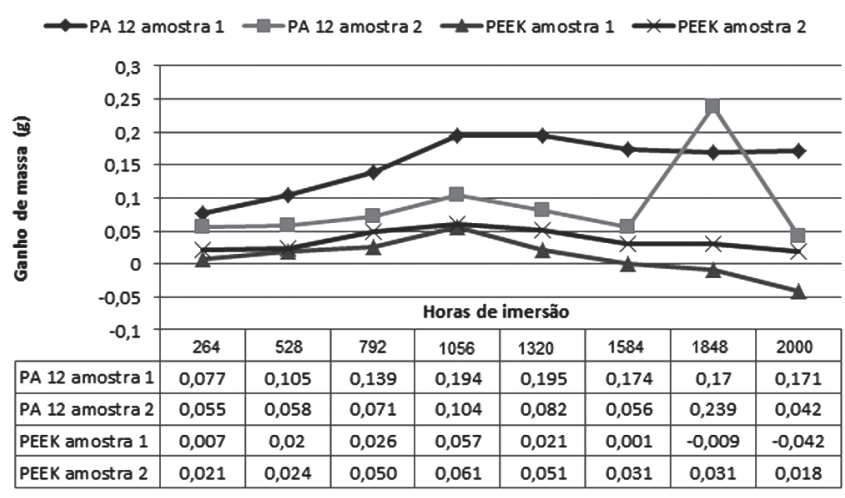

Figura 9. Resultados em ganho de massa do ensaio de corrosão de acordo com a norma ASTM D1308-02- 2007

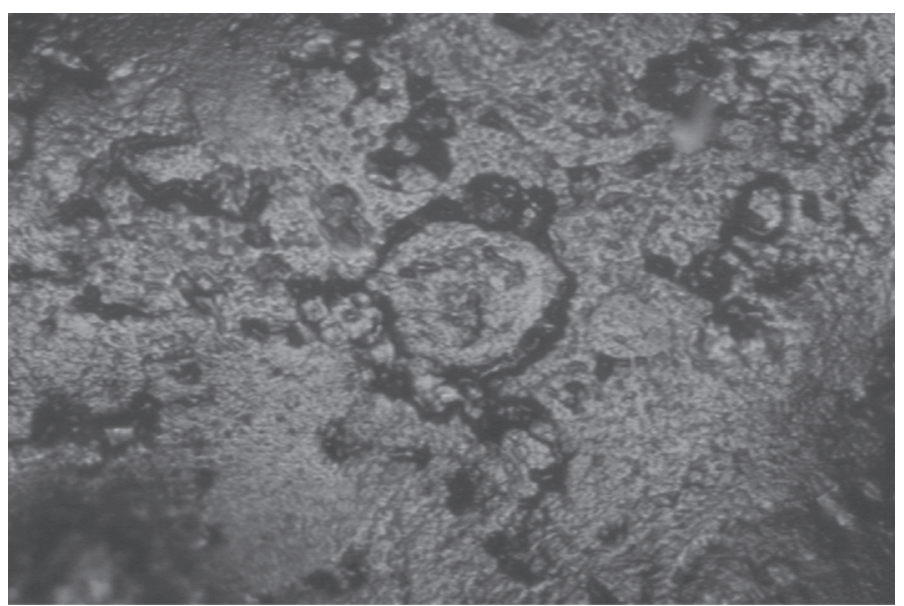

b)

Figura 10. Imagem representativa da superfície dos revestimentos a) PA 12 e b) PEEK após 2000 horas em imersão no ensaio de corrosão. 


\section{Conclusões}

Neste trabalho, foram aplicados revestimentos poliméricos poli-éter-éter-cetona (PEEK) e Poliamida 12 sobre substratos de aço carbono, utilizando o processo de aspersão térmica a chama convencional. Foram avaliadas as características dos materiais e dos revestimentos obtidos, especialmente quanto às propriedades mecânicas, de desgaste e corrosão.

Pelos resultados da avaliação por microscopia ótica e de varredura, os revestimentos obtidos se mostraram adequados para aplicação sobre substratos metálicos, não apresentando delaminação, evidenciando poucos defeitos e homogeneidade.

Os revestimentos PEEK e Poliamida 12 avaliados apresentaram, comparativamente, resultados bastante similares nos ensaios de desgaste e de corrosão, apesar de uma das amostras de Poliamida 12 ter apresentado maior perda de massa no ensaio de desgaste e maior ganho de massa no ensaio de corrosão, provavelmente em função de alguma alteração microestrutural não detectada pela caracterização efetuada.

Considerando-se eventuais diferenças nos custos de aquisição dos materiais, além das especificidades da aplicação do revestimento, pode-se afirmar que ambos, PEEK e Poliamida 12 podem ser usados com efetividade na proteção contra desgaste e corrosão combinados de componentes metálicos de diversas indústrias, como em componentes de bombas e dutos na indústria de óleo e gás.

\section{Agradecimentos}

Os autores agradecem ao LTAD - Laboratório de Tecnologia em Atrito e Desgaste da Universidade Federal de Uberlândia, pela realização dos ensaios de desgaste e ao Grupo Labmat, pelos ensaios de corrosão.

\section{Referências Bibliográficas}

[1] AWS - American Welding Society Thermal Spraying, Practice, Theory and Applications, Miami, FL, USA, 1985.

[2] LIMA, C.R.C., TREVISAN, R.E. Aspersão Térmica: Fundamentos e Aplicações. $2^{\text {nd }}$ ed., São Paulo, Artliber, 2007. $152 \mathrm{p}$.

[3] DAVIS, J. R. (Ed.). Handbook of Thermal Spray Technology. New York, ASM International, 2004. 338 p.

[4] HERMAN, H., SAMPATH, S., McCUNE, R., Thermal Spray: Current Status and Future Trends. MRS Bulletin, USA, v.25, p.17-25, 2000.

[5] PAWLOWSKI, L. The Science and Engineering of Thermal Spray Coatings, New York, John Wiley \& Sons. 1995.

[6] WIEBECK, H.; HARADA, J. Plásticos de Engenharia: Tecnologia e Aplicações, São Paulo, Artliber, 2005.

[7] CALLISTER Jr., W. D. Ciência e Engenharia de Materiais, $5^{\mathrm{a}}$. ed. Rio de Janeiro, LTC, 2002.

[8] SPERLING, L.H. Introduction to Physical Polymer Science, London, Wiley Interscience Publication, 1992.

[9] VICTREX, PEEK: Properties Guide, Lancashire, 2002.
[10] SOVEJA, A., SALlAMAND, P., LIAO, H., COSTIL, S., Improvement of flame spraying PEEK coating characteristics using lasers. Journal of Materials Processing Technology., v.211-1, p.12-23. 2011.

[11] ALAMARA, K., SABER-SAMANDARI, S., BERNDT, C.C., Splat formation of polypropylene flame sprayed onto a flat surface. Surface and Coatings Technology, v.205, p.2518-2524, 2010.

[12] AMERICAN SOCIETY FOR TESTING AND MATERIALS. ASTM D1308 - 02(2007) Standard Test Method for Effect of Household Chemicals on Clear and Pigmented Organic Finishes. v.06.02, Feb. 2012 Paint -- Products and Applications; Protective Coatings; Pipeline Coatings.

[13] TURI, E. A. (Ed.) Thermal Characterization of Polymeric Materials. $2^{\text {nd }}$ ed., San Diego, Califórnia, Academic Press, volume 1, 1997. $1210 \mathrm{pp}$.

[14] CANEVAROLO JR, S. V., Técnicas de Caracterização de Polímeros. a $^{\text {a }}$ ed. São Paulo: Artliber Editora Ltda., 2003. 448p. 